\title{
Dietary Diacylglycerol-Rich Oil Stimulation of Glucose Intolerance in Genetically Obese Rats
}

\author{
Tomomi Sugimoto, Hitomi Fukuda, Tomoe Kimura and Nobuko IrITAnI* \\ Faculty of Human and Cultural Studies, Tezukayama Gakuin University, \\ 4-2-2 Harumidai, Sakai, Osaka 590-0113, Japan
}

(Received December 24, 2002)

\begin{abstract}
Summary The effects of dietary 1,3-diacylglycerol-rich oil (DG oil) on glucose and lipid metabolism were investigated in comparison with triacylglycerol (TG) oil in female genetically obese Wistar fatty rats. The obese rats and their lean littermates ( $8 \mathrm{wk}$ old) were fed a synthetic diet containing $10 \%(\mathrm{w} / \mathrm{w})$ DG or TG oil for $5 \mathrm{wk}$. The body weights, abdominal fat weights, and the plasma and liver TG concentrations were not significantly different due to dietary fat type in the obese and lean rats. The plasma glucose concentrations were significantly elevated by dietary DG oil as compared to TG oil in the portal vein and inferior vena cava of obese and lean rats. The plasma free fatty acid concentrations were markedly elevated by dietary DG oil as compared to TG oil in the portal vein and inferior vena cava of both genotype rats, particularly in the obese rats. In the glucose tolerance test, the obese rats fed DG oil showed glucose intolerance, possibly due to the markedly elevated plasma free fatty acids. Thus, the effects of dietary DG oil on lipid-lowering effects and anti-obesity were not observed in either genotype in the present study. Moreover, it is remarkable that glucose intolerance was induced by dietary DG oil in the genetically obese rats.
\end{abstract}

Key Words dietary DG, free fatty acid, glucose intolerance, obese rats

Several studies on the lipid lowering effects of 1,3-diacylglycerol-rich oil (DG oil) have been reported from the research laboratories of a company that produces DG oil. In these studies (1-4), DG oil suppressed the accumulation of fat as compared to triacylglycerol (TG) oil in humans and rats, and possibly reduced the risk of diseases associated with visceral fat obesity. Oral intubation of an emulsion containing DG oil reduced the serum TG levels as compared to TG oil infusion in rats and markedly elevated the portal vein free fatty acid levels (1). However, the energy values and apparent digestibility of the DG and TG oils were similar (5). Thus, they suggested that the reduction of fat accumulation by dietary DG oil might be ascribed to a different absorption mechanism from that for TG oil.

Increased plasma free fatty acid concentrations have commonly been associated with impaired insulin-mediated glucose uptake and with many insulin-resistant states $(6,7)$. Fatty acid-rich medium reduced insulin receptor tyrosin kinase activity in rat hepatoma cells (8). Dresner et al. (9) concluded that increased concentrations of plasma free fatty acids induce insulin resistance in humans through the inhibition of glucose transport activity. Therefore, extensive physiological and nutritional studies on DG oil are required before the synthetic oil can be recommended for use in daily diets.

A synthetic oil product containing a high level of DG

* To whom correspondence should be addressed.

E-mail: iritani@hcs.tezuka-gu.ac.jp

Abbreviations: DG, diacylglycerols; TG, triacylglycerols; PUFA, polyunsaturated fatty acids. oil (55\% 1,3-DG, 25\% 1,2-DG and 20\% TG) (4) is now commercially available. Natural edible oil contains 1,2DG and 1,3-DG as minor components. 1,2-DG is converted to 1,3-DG by acyl migration in edible oils (10). 1,2-DG is an intermediate of TG digestion in the intestine. However, further studies on the health safety of DG oil (containing such a high level of DG, $80 \%$ in total) should be investigated.

A genetically obese Wistar fatty rat with non-insulindependent diabetes mellitus was produced by combining the insulin resistance of the Wistar Kyoto strain with the fa gene of the Zucker strain for obesity (11). The male Wistar fatty rats are obese, hyperglycemic, hyperphagic, hyperinsulinemic, and hypertriglyceridemic. They also show impaired glucose tolerance and a glycemic response to exogenous insulin $(11,12)$. However, the female rats are obese, hyperinsulinemic, and hypertriglyceridemic, but normoglycemic. In the present study, we have investigated the effects of dietary DG oil on glucose and lipid metabolism as compared to TG oil and those of increased free fatty acids on insulin resistance in the genetically obese type of female Wistar fatty rat.

\section{MATERIALS AND METHODS}

Materials. The insulin assay kit was obtained from Eiken Chemical Company (Tokyo, Japan). Most other reagents were obtained from Wako (Osaka, Japan) and from Sigma (St. Louis, MO, USA). For dietary fat, Nisshin salad oil (a mixture of rapeseed oil and soyean oil, Nisshin Oilio Co., Tokyo) was used as the TG oil, and Kao Econa (Kao Co., Tokyo) was used as the DG oil, 
which contained 53.8\% 1,3-DG, 27.6\% 1,2-DG, and $18.6 \%$ TG.

Animals. Female genetically obese Wistar fatty rats $(\mathrm{fa} / \mathrm{fa})$ and their lean littermates $(\mathrm{Fa} / \mathrm{Fa}, \mathrm{fa} / \mathrm{Fa})(11)$ were obtained from Takeda Chemical Industries, Ltd. (Osaka, Japan). The female Wistar fatty rats were hypertriglyceridemic and hyperinsulinemic, but normoglycemic. At $8 \mathrm{wk}$ of age, the rats were fed a $10 \mathrm{~g} / 100 \mathrm{~g}$ diet of DG oil or TG oil for $5 \mathrm{wk}$. The diet compositions were $563 \mathrm{~g} \mathrm{su}$ crose, $200 \mathrm{~g}$ casein, $100 \mathrm{~g}$ DG or TG oil, $95 \mathrm{~g}$ cellulose, $40 \mathrm{~g}$ salt mixture (13), $1 \mathrm{~g}$ choline chloride, and $1 \mathrm{~g}$ vitamin mixture (13). The major fatty acid compositions of DG oil used were $(\mathrm{g} / 100 \mathrm{~g}$ total fatty acids): $16: 0$, $4.57 ; 18: 0,1.62 ; 18: 1,39.8 ; 18: 2,49.9$; and $18: 3$, 4.19 , and those of TG oil, $16: 0,8.46 ; 18: 0,2.59 ; 18$ : $1,49.3 ; 18: 2,34.5$, and $18: 3,5.15$. Rats were individually housed in wire-bottomed cages in a temperature-controlled room $\left(24^{\circ} \mathrm{C}\right)$ under an automatic lighting schedule (0800 to $2000 \mathrm{~h}$ ). The rats had free access to water and were given equal energy-containing diets per body weight per day in the DG and TG oil groups for each genotype. The amount of diet consumed by a rat was measured at $1700 \mathrm{~h}$ every day, and based on the measurement, the expected amount of diet consumed was given for the following day. The spontaneous food consumption was similar in the $10 \%$ (by weight) DG and TG oil groups.

The rats were sacrificed between 0900 and $1000 \mathrm{~h}$. The rats were decapitated after blood was taken using a heparinized syringe from the portal vein and then inferior vena cava while under diethyl ether anesthesia. Plasma was obtained to determine the concentrations of glucose, insulin, free fatty acids, and ketone bodies by centrifuging of heparinized blood at $4^{\circ} \mathrm{C}$ for $20 \mathrm{~min}$ at $1,200 \times g$. The fresh plasma was used to determine glucose and insulin concentrations. The rest of the plasma was stored at $-80^{\circ} \mathrm{C}$ until used to measure the concentrations of free fatty acids and ketone bodies. The liver and abdominal white adipose tissues were also stored at $-80^{\circ} \mathrm{C}$ to measure mRNA concentrations of the insulin receptors. Care and treatment of experimental animals were in accordance with guidelines, Animal Care and Use of Tezukayama Gakuin University, that are similar to the Guide for the Care and Use of Laboratory Animals (14).

The oral glucose tolerance test was done at $4 \mathrm{wk}$ of feeding experimental diets, $1 \mathrm{wk}$ before the rats were sacrificed. Rats were given a $400 \mathrm{~g} / \mathrm{L}$ glucose solution (3 g glucose/kg body weight) by stomach tube after being deprived of food for $20 \mathrm{~h}$. Blood was taken with a heparinized syringe from the tail vein.

Dot blot and Northern blot hybridization assays. Human insulin receptor cDNA (15) was a generous gift from Professor Y. Ebina (Institute for Enzyme Research, University of Tokushima, Japan). The genomic clone of rat rRNA was obtained from the Japanese Cancer Research Resources Bank (Mishima, Japan). A fragment of about $1 \mathrm{~kb} \mathrm{BamHI/EcoRI}$ of this clone was isolated and used as a probe for $18 \mathrm{~S}$ rRNA. Total RNA was isolated from liver and adipose tissues by acid guanidium thiocyanate-phenol-chloroform extraction (16). To measure the mRNA concentrations of insulin receptors, the total RNA (10-30 $\mu \mathrm{g})$ was denatured with formamide, spotted on a nylon filter, and then radiated with ultraviolet light for $5 \mathrm{~min}$. The filter was prehybridized and then hybridized with ${ }^{32} \mathrm{P}$-labeled cDNA as described previously (17). Relative densities of the hybridization signals were determined by scanning the autoradiograms at $525 \mathrm{~nm}$ and normalized to the values of $18 \mathrm{~S}$ rRNA. The mRNA concentrations were measured by the dot blot hybridization method, and many of them were confirmed by Northern blot analysis.

Northern blot analysis of RNA was performed as described by Gonzales and Kasper (18). Total RNA was denatured and electrophoresed on a 1.0\% agarose gel containing $2.2 \mathrm{~mol} / \mathrm{L}$ formaldehyde. The gel was blotted onto a nylon filter according to Thomas (19). Details of prehybridization, hybridization, and autoradiography were as described previously (17). The autoradiograms of the Northern blot analysis of insulin receptors were shown in our previous report (20).

Analyses. Plasma glucose concentrations were determined by the glucose-oxidase method (21). Plasma insulin concentrations were measured by a two-antibody system radioimmunoassay according to the method of Morgan and Lazarow (22). Plasma and liver TG concentrations were measured by the method of Fletcher (23). The concentrations of plasma free fatty acids and total ketone bodies were measured by the methods of Kushiro and Fukui (24) and Harano et al. (25), respectively.

Statistical analysis. Two-way ANOVA was followed by inspection of all differences between pairs of means using the least significant difference test (26). Differences were considered significant at $p<0.05$.

\section{RESULTS}

\section{Animal profiles}

The final body weights, liver weights $(\mathrm{g} / 100 \mathrm{~g} \mathrm{bw})$, and abdominal fat weights of obese rats and their lean littermates are shown in Table 1. The body weights, liver weights, abdominal fat weights, and feed efficiencies were significantly larger in obese rats than in lean rats, but were not significantly different due to dietary fat.

Effects of dietary fat types on plasma glucose and insulin concentrations

The plasma glucose concentrations were significantly higher $(p<0.05)$ in the portal vein and inferior vena cava of rats fed DG oil as compared to those fed TG oil (Fig. 1). The plasma insulin concentrations in the portal vein were significantly higher $(p<0.05)$ in lean rats fed DG oil than in those fed TG oil. The insulin concentrations in both veins were markedly higher $(p<0.001)$ in obese rats than in the lean rats.

Effects of dietary fat types on plasma free fatty acid and ketone body concentrations

The plasma free fatty acid concentrations of the portal vein and inferior vena cava were higher $(p<0.001)$ in the DG oil group than in the TG oil group of the obese 
Table 1. Body weights, liver weights, abdominal fat weights, and feed efficiency. ${ }^{1}$

\begin{tabular}{|c|c|c|}
\hline Dietary fat & Lean & Obese \\
\hline \multicolumn{3}{|c|}{ Body weight, $g$} \\
\hline DG oil & $243 \pm 11.8$ & $417 \pm 34.4$ \\
\hline TG oil & $237 \pm 22.4$ & $412 \pm 24.5$ \\
\hline \multicolumn{3}{|c|}{ Liver weight, $\mathrm{g} / 100 \mathrm{~g}$ body weight } \\
\hline DG oil & $4.57 \pm 0.16$ & $4.93 \pm 0.79$ \\
\hline TG oil & $4.15 \pm 0.35$ & $4.98 \pm 0.39$ \\
\hline \multicolumn{3}{|c|}{ Abdominal fat weight, $\mathrm{g} / 100 \mathrm{~g}$ body weight } \\
\hline DG oil & $3.48 \pm 0.36$ & $8.82 \pm 1.12$ \\
\hline TG oil & $3.81 \pm 0.67$ & $8.76 \pm 0.76$ \\
\hline \multicolumn{3}{|c|}{$\begin{array}{l}\text { Feed efficiency, body weight gain, } \mathrm{g} / 100 \mathrm{~g} \text { food } \\
\text { consumption }\end{array}$} \\
\hline DG oil & $11.3 \pm 1.88$ & $16.7 \pm 2.25$ \\
\hline TG oil & $9.45 \pm 2.28$ & $18.5 \pm 1.29$ \\
\hline
\end{tabular}

${ }^{1}$ Values are means \pm SD, $n=7$. The lean and obese rats $(8$ wk-old) were pair-fed DG and TG oil diets as described in Materials and Methods. The body weights at the start of the experiment were not significantly different in the DG and TG oil groups (g): $177 \pm 14.2$ and $176 \pm 14.4$, respectively, in the lean rats, and $265 \pm 9.29$ and $260 \pm 7.26$, respectively, in the obese rats. The feed efficiency was calculated as body weight gain ( $\mathrm{g}$ )/food consumption $(100 \mathrm{~g})$ for the feeding period. Significantly different due to genotype in body weights, liver weights, abdominal fat weights, and feed efficiencies, $p<0.001$; in liver weights, $p<0.01$. No significances due to dietary fat type in body weights, liver weights, abdominal fat weights, or feed efficiency of each genotype.

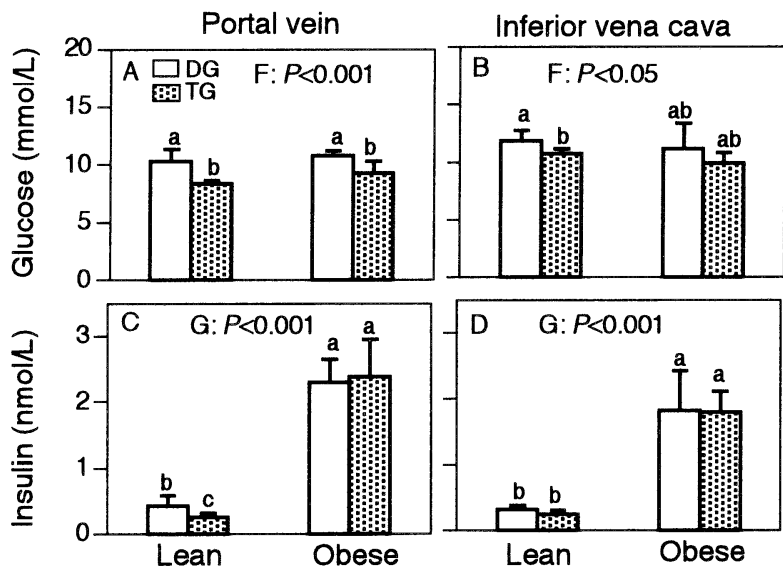

Fig. 1. Effects of dietary fat types on plasma glucose and insulin concentrations in the portal vein and inferior vena cava of obese and lean rats. The genetically obese rats and their lean littermates were fed $10 \%$ (w/w) DG or TG oil diets for $5 \mathrm{wk}$. Panels A and B show the plasma glucose concentrations of the portal vein and inferior vena cava, respectively, and panels $\mathrm{C}$ and $\mathrm{D}$, the corresponding insulin concentrations, respectively. Values are means \pm SD, $n=7$. Two-way ANOVA in each panel, F, dietary fat main effect; G, genotype main effect. Means with different letters in each figure are significantly different $(p<0.05)$.

and lean rats, particularly in the obese rats (Fig. 2). The free fatty acid concentrations were higher $(p<0.001)$ in the portal vein than in the inferior vena cava. The

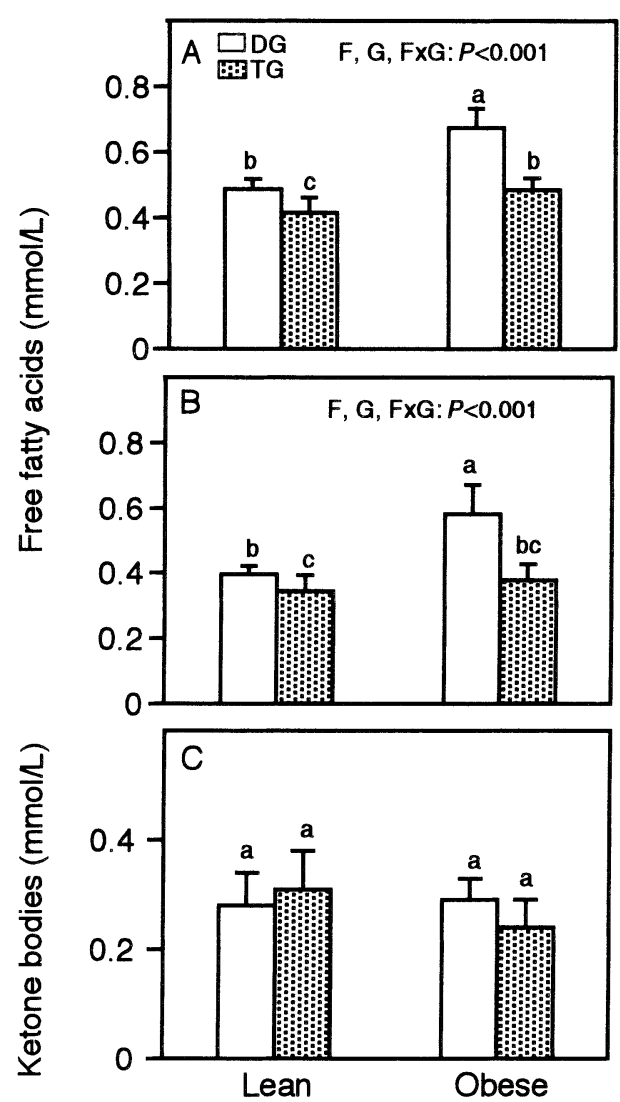

Fig. 2. Effects of dietary fat types on plasma free fatty acid and ketone body concentrations of obese and lean rats. The plasma free fatty acid concentrations in portal vein (panel A) and inferior vena cava (panel B) of the same rats referenced in Fig. 1 are shown. Values are means $\pm \mathrm{SD}, n=7$. Two-way ANOVA in each panel, F, dietary fat main effect; G, genotype main effect, $\mathrm{F} \times \mathrm{G}$, interaction. Means with different letters in each figure are significantly different $(p<0.05)$.

plasma ketone body concentrations were not significantly different due to dietary fat types and genotypes. Effects of dietary fat types on TG concentrations

The plasma TG concentrations in the portal vein and inferior vena cava of both obese and lean rats were not significantly different in the DG and TG oil groups (Table 2). The liver TG concentrations were also not significantly different between the dietary fat types. The plasma and liver TG concentrations were markedly higher $(p<0.001)$ in the obese rats than in the lean rats.

Effects of dietary fat types on increments of plasma glucose and insulin concentrations in the glucose tolerance test

The increments of plasma glucose and insulin levels in response to an oral glucose load in a typical experiment are shown in Fig. 3. Comparable increments in the glucose and insulin values (0 to 120 min after glucose intubation) were calculated from the increment values (Table 3). The increments in glucose values were not significantly different due to dietary fat type in the lean rats. In the obese rats, however, the increments in glucose values were significantly elevated $(p<0.05)$ by dietary DG oil as compared to TG oil. Consequently, the increments in glucose values were significantly higher 
Table 2. Effects of dietary fat types on plasma and liver TG concentrations of obese and lean rats.

\begin{tabular}{|c|c|c|c|}
\hline \multirow[b]{2}{*}{ Dietary fat } & \multicolumn{3}{|c|}{ TG concentrations $^{1}$} \\
\hline & Portal vein & $\begin{array}{c}\text { Inferior vena } \\
\text { cava } \\
\mathrm{mmol} / \mathrm{L}\end{array}$ & $\begin{array}{c}\text { Liver } \\
\mu \mathrm{mol} / \mathrm{g} \text { liver }\end{array}$ \\
\hline \multicolumn{4}{|l|}{ Lean } \\
\hline DG oil & $1.03 \pm 0.16$ & $1.11 \pm 0.14$ & $13.6 \pm 2.81$ \\
\hline TG oil & $1.07 \pm 0.28$ & $1.06 \pm 0.20$ & $10.6 \pm 1.86$ \\
\hline \multicolumn{4}{|l|}{ Obese } \\
\hline DG oil & $2.61 \pm 0.18$ & $2.98 \pm 0.42$ & $123 \pm 30.5$ \\
\hline TG oil & $2.84 \pm 0.62$ & $2.79 \pm 0.57$ & $136 \pm 20.9$ \\
\hline $\begin{array}{l}\text { ANOVA } \\
\qquad(p<0.001)^{2}\end{array}$ & G & G & G \\
\hline
\end{tabular}

${ }^{1}$ Values are means $\pm S D, n=7$. The plasma and liver TG concentrations of the same rats of Fig. 1 are shown.

${ }^{2}$ Two-way ANOVA in each column: G, genotype main effect. No significant difference was found due to dietary fat.

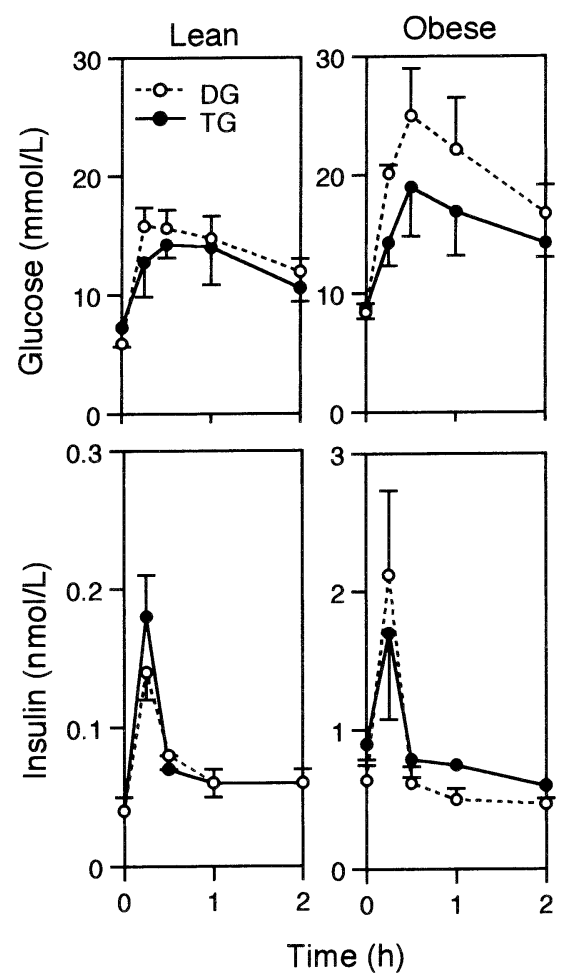

Fig. 3. Effects of dietary fat types on plasma glucose (upper) and insulin (lower) concentrations of lean (left) and obese rats (right) in the glucose tolerance test. The oral glucose tolerance test was done $1 \mathrm{wk}$ before the rats were sacrificed. Rats received a $400 \mathrm{~g} / \mathrm{L}$ glucose solution ( $3 \mathrm{~g}$ glucose $/ \mathrm{kg}$ body weight) by stomach tube after being deprived of food for $20 \mathrm{~h}$. Blood was taken with a heparinized syringe from the tail vein. One of the typical experiments, which results are included in Table 3, is shown. Values are means $\pm \mathrm{SD}, n=3$.

in the obese rats fed DG as compared to the lean rats.

The increments of insulin values were not significantly different between dietary fat types in the obese
Table 3. Effects of dietary fat types on increment values of plasma glucose and insulin concentrations in glucose tolerance test.

\begin{tabular}{lcc}
\hline & \multicolumn{2}{c}{ Increments from basal levels ${ }^{1,2}$} \\
\cline { 2 - 3 } Dietary fat & $\begin{array}{c}\text { Glucose area } \\
\mathrm{mmol} / \mathrm{L} / 2 \mathrm{~h}\end{array}$ & $\begin{array}{c}\text { Insulin area } \\
\mathrm{pmol} / \mathrm{L} / 2 \mathrm{~h}\end{array}$ \\
\hline Lean & & \\
DG oil & $12.1 \pm 3.85^{\mathrm{b}}$ & $92.7 \pm 20.2^{\mathrm{b}}$ \\
TG oil & $9.90 \pm 1.54^{\mathrm{b}}$ & $74.8 \pm 12.3^{\mathrm{b}}$ \\
Obese & & \\
DG oil & $20.7 \pm 4.48^{\mathrm{a}}$ & $403 \pm 99.8^{\mathrm{a}}$ \\
TG oil & $10.9 \pm 2.70^{\mathrm{b}}$ & $367 \pm 109^{\mathrm{a}}$ \\
ANOVA $(p<0.05)^{3}$ & $\mathrm{~F}, \mathrm{G}, \mathrm{FxG}$ & $\mathrm{G}$ \\
\hline
\end{tabular}

\footnotetext{
${ }^{1}$ Values are means $\pm \mathrm{SD}, n=6$.

${ }^{2}$ Increment from basal levels of plasma glucose or insulin concentration in the glucose tolerance test were calculated as: area $=(A+2 B+3 C+6 D+4 E) \times 1 / 8-2 A$ $(\mathrm{mmol} / \mathrm{L} / 2 \mathrm{~h}$ or $\mathrm{pmol} / \mathrm{L} / 2 \mathrm{~h})$, where $A$ represents the level of each index before oral glucose load, and $B, C, D$, and $E$ are the levels at $15,30,60$, and $120 \mathrm{~min}$ after glucose intubation, respectively.

${ }^{3}$ Two-way ANOVA of glucose or insulin increment; F, dietary fat main effect; G, genotype main effect; FxG, interaction. Means with different letters in each column are significantly different $(p<0.05)$
}

and lean rats. The increments of insulin values were markedly higher $(p<0.01)$ in obese rats fed either diet than in the lean rats. Thus, in the glucose tolerance test, dietary DG oil stimulated glucose intolerance as compared to TG oil in the obese rats.

Effects of dietary fat types on $m R N A$ expressions of insulin receptors

The insulin receptor mRNA expressions in liver and abdominal adipose tissues were not significantly different between the dietary fat groups of the obese and lean rats (Fig. 4). The insulin receptor expressions of the adipose tissues were markedly lower $(p<0.001)$ in the obese rats than in the lean rats, whereas the expressions of liver were not different between the groups.

\section{DISCUSSION}

In the present study, in genetically obese Wistar fatty rats fed a synthetic diet containing 10\% (by weight, $22.4 \%$ by calorie) DG oil for $5 \mathrm{wk}$, the body weights and abdominal fat weights were not significantly different as compared to rats fed a diet containing TG oil. The plasma and liver TG concentrations were also not significantly different between both oils. However, Murase et al. reported that, in obesity-prone $\mathrm{C} 57 \mathrm{BL} / 6 \mathrm{~J}$ mice fed a diet containing $30 \%$ (by weight, $52.8 \%$ by calorie) DG oil for 5 mo, body weight gain and visceral fat weight were reduced by $70 \%$ and $79 \%$, respectively, as compared to a TG oil-fed group (27).

Moreover, their group also reported that, in healthy male humans, body weight, BMI, and waist circumfer- 
ence were decreased by the intake of only $10 \mathrm{~g} / \mathrm{d}$ of DG oil ( $4.9 \%$ by calorie) for $16 \mathrm{wk}$ as compared to controls fed TG oil (4). Total fat, visceral fat area, and subcutaneous fat area of the abdominal traverse images of computed tomography were also reduced by dietary DG oil. In another report (1), the plasma TG levels and body fat ratio were significantly reduced in normal rats fed a $10 \%$ (by weight) DG oil diet for 3 and $4 \mathrm{wk}$ as compared to the TG oil diet. In our previous study of normal rats, however, significant effects of dietary DG oil on body weights, abdominal fat weights, and plasma TG levels were not observed in rats fed $10 \%$ (by weight, $22.4 \%$ by calories) DG oil for 1-12 wk (28). Although they found DG oil lipid-lowering effects on humans (4), rats (1), and obese mice (27), we could not find the DG oil effects in normal and obese rats. They did not provide a description of paired-feeding between the DG and TG oil groups. Since dietary energy and nutrient compositions greatly influence the lipid lowering effects, paired-feeding is important in this kind of experiment.

It is well known that polyunsaturated fatty acids (PUFA) suppress fatty acid synthesis and then TG levels. The DG and TG oils used in the present study contained 55\% and $40 \%$ PUFA, respectively. The fatty acid compositions are described in Materials and Methods. Although the plasma and liver TG concentrations increased with increasing dietary PUFA contents, the concentrations began leveling off (29). Based on these results, the effects of the difference in PUFA contents of the oils on TG concentrations were suggested to be worth only slight consideration in the present experiments. Incidentally, although the PUFA contents were higher in the DG oil diet than in the TG oil diet, lipidlowering effects were not found in the DG oil group.

Increased plasma free fatty acid concentrations were commonly associated with impaired insulin-mediated glucose uptake and many insulin-resistant states $(6,7)$. Fatty acid-rich medium reduced insulin receptor tyrosine kinase activity in rat hepatoma cells (8). Dresner et al. (9) concluded that increased concentrations of plasma free fatty acid induce insulin resistance in humans through the inhibition of glucose transport activity, probably as a consequence of decreased IRS-1-associated PI 3-kinase activity. Griffin et al. (30) reported that increased insulin resistance was associated with abnormalities in the insulin-signaling cascade and may be mediated by the free fatty acid activation of protein kinase $\mathrm{C} \theta$.

In the present study, the plasma free fatty acid concentrations were markedly elevated by dietary DG oil as compared to TG oil in both genotype rats, particularly in the obese. It was also reported that, after intragastric infusion of an emulsion containing DG oil, portal vein free fatty acids were markedly elevated as compared to TG oil (1). In the glucose tolerance test, the obese rats fed DG oil showed an elevated glucose intolerance as compared to TG oil. Thus, it is suggested that dietary DG oil may induce insulin resistance due to the marked increase of plasma free fatty acid concentrations in the obese rats. Since the insulin receptor expressions of the

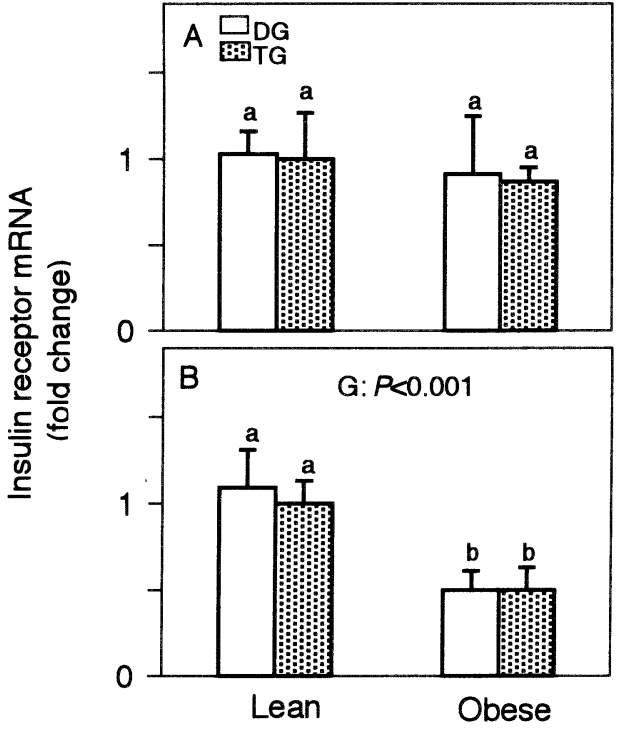

Fig. 4. Effects of dietary fat types on insulin receptor mRNA concentrations of obese and lean rats. The insulin receptor mRNA concentrations of the same rats referenced in Fig. 1 are shown. The insulin receptor mRNA concentrations in the liver (panel A) and abdominal white adipose tissues (panel B) are shown. The mRNA concentrations were normalized to each panel for lean rats fed the TG oil diet. Values are means \pm SD, $n=7$. Two-way ANOVA in each panel, G, genotype main effect: $p<0.001$ for insulin receptor mRNA concentrations in the adipose tissues. Means with different letters in each figure are significantly different $(p<0.05)$.

liver and adipose tissues were not different in the dietary oil groups, insulin resistance should be ascribed to the insulin receptor activities. The insulin binding capacities were too low for us to measure satisfactorily.

Although plasma and liver TG concentrations were markedly high in the obese rats, the TG concentrations were not reduced by dietary DG oil. The body weights and abdominal fat weights were not reduced by dietary DG oil. Thus, the lipid-lowering effects of dietary DG oil on the TG concentrations and the abdominal fat weight, were not observed in both obese and lean rats in the present experiment. Moreover, glucose intolerance was observed in the obese rats fed DG oil. Further studies on the health safety of DG oil (containing such a high level of DG, $80 \%$ in total) should be investigated, particularly in the case of ingesting considerable amounts of DG oil as daily food for obese subjects.

\section{Acknowledgments}

This work was supported by Tezukayama Gakuin University. We wish to acknowledge Takeda Chemical Industries, Ltd. for providing the genetically obese Wistar fatty rats.

\section{REFERENCES}

1) Watanabe H, Onizawa K, Taguchi H, Kobori M, Chiba H, Naito S, Matsuo N, Yasukawa T, Hattori M, Shimasaki H. 1997. Nutritional characterization of dia- 
cylglycerols in rats. J Jpn Oil Chem Soc 46: 301-307.

2) Watanabe H, Onizawa K, Taguchi H, Fujimori N, Naito S, Gotoh N, Yasukawa T, Hattori M, Shimasaki H. 1997. Effects of diacylglycerols on lipid metabolism in human. J Jpn Oil Chem Soc 46: 6309-6314.

3) Watanabe H, Nagao T, Gotoh N, Fukushima Y, Onizawa K, Taguchi H, Ohmachi T, Yasukawa T, Naito S, Shimasaki H, Itakura H. 1998. Long-term effects of dietary diacylglycerols on body fat metabolism. J Jpn Oil Chem Soc 47: 369-376.

4) Nagao T, Watanabe H, Goto N, Onizawa K, Taguchi H, Matsuo N, Yasukawa T, Tsushima R, Shimasaki H, Itakura H. 2000. Dietary diacylglycerol suppresses accumulation of body fat compared to triacylglycerol in men in a double-blind controlled trial. J Nutr 130: 792-797.

5) Taguchi $\mathrm{H}$, Nagao T, Watanabe H, Onizawa K, Matsuo N, Tokimitsu I, Itakura H. 2001. Energy value and digestibility of dietary oil containing mainly 1,3-diacylglycerol are similar to those of triacylglycerol. Lipids $\mathbf{3 6}$ : 379-382.

6) Frayn KN. 1993. Insulin resistance and lipid metabolism. Curr Opin Lipidol 4: 197-204.

7) Steiner G, Morita S, Vranic M. 1980. Resistance to insulin but not to glucagons in lean human hypertriglyceridemics. Diabetes 29: 899-905.

8) Huber P, Bruneau-Wack C, Cremel G, LeMarchandBrustel Y, Staedel C. 1991. Lipid-induced insulin resistance in cultured hepatoma cells is associated with a decreased insulin receptor tyrosin kinase activity. Cell Regul. 2: 65-72.

9) Dresner A, Laurent D, Marcucci M, Griffin ME, Dufour S, Cline GW, Slezak LA, Andersen DK, Hundal RS, Rothman DL, Peterson KF, Shulman GI. 1999. Effects of free fatty acids on glucose transport and IRS-1-associated phosphatidylinositol 3-kinase activity. J Clin Invest 103: 253-259.

10) Crossley A, Freeman IP, Hudson JF, Pierce JH. 1959. Acyl migration in diglycerides. J Chem Soc: 760-764.

11) Ikeda $H$, Shino A, Matsuo T, Iwatsuka H, Suzuoki Z. 1981. A new genetically obese-hyperglycemic rat (Wistar fatty). Diabetes 30: 1045-1050.

12) Matsuo T, Ikeda H, Iwatsuka H, Suzuoki Z. 1984. Predisposition to hyperglycemia and hypertriglyceridemia in two genetically obese rats-Wistar and Zucker fatty rat. In: Lessons from Animal Diabetes (Shafrir E, Renold AE, eds), p 257-260. John Libbey, London and Paris.

13) Reeves PG, Nielsen FH, Fahey GC Jr. 1993. Purified diets for laboratory rodents: final report of the American Institute of Nutrition and hoc writing committee on the reformation of the AIN-76A rodent diet. J Nutr 123: 1939-1951.

14) National Research Council. 1985. Guide for the Care and Use of Laboratory Animals. Publication no. 85-23 (rev.), National Institute of Health, Bethesda, MD.

15) Ebina Y, Ellis L, Jamagin K, Edery M, Graf L, Clauser E, Ou J-H, Masiartz F, Kan YW, Goldfine ID, Roth RA, Rutter W. 1985. The human insulin receptor cDNA: the structural basis for hormone-activated transmembrane signaling. Cell 40: 747-758.

16) Chomczynski P, Sacchi N. 1987. Single-step method of RNA isolation by acid guanidium thiocyanate-phenolchloroform extraction. Anal Biochem 163: 156-159.

17) Katsurada A, Iritani N, Fukuda H, Matsumura $Y$, Nishimoto N, Noguchi T, Tanaka T. 1990. Effects of nutrients and hormones on transcriptional and post-transcriptional regulation of fatty acid synthase in rat liver. Eur J Biochem 190: 427-433.

18) Gonzales FJ, Kasper CB. 1982. Cloning of DNA complementary to rat liver NADPH-cytochrome c (P-450) oxidoreductase and cytochrome P-450b mRNAs. J Biol Chem 257: 5962-5968.

19) Thomas PS. 1980. Hybridization of denatured RNA and small DNA fragments transferred to nitrocellulose. Proc Natl Acad Sci USA 77: 5201-5205.

20) Iritani N, Sugimoto T, Fukuda H. 2000. Gene expressions of leptin, insulin receptors and lipogenic enzymes are coordinately regulated by insulin and dietary fat in rats. J Nutr 130: 1183-1188.

21) Werner W, Rey H-G, Wielinger H. 1970. Uber die Eigenschaften eves neuen Chromogens fur die Blutzucherbestimmung nach der GOD/POD-Methode. Anal Chem 252: 224-228.

22) Morgan CR, Lazarow A. 1963. Immunoassay of insulin: Two antibody system plasma insulin levels of normal, subdiabetic and diabetic rats. Diabetes 12: 115-126.

23) Fletcher MJ. 1968. A calorimetric method for estimating serum triglycerides. Clin Chim Acta 22: 393-397.

24) Kushiro H, Fukui I. 1971. Quantitation of free fatty acid. Clin Chem 1: 42-51.

25) Harano Y, Kosugi K, Hyosu T, Ueno S, Ichikawa Y, Shigeta Y. 1983. Sensitive and simplified method for the differential determination of serum levels of ketone bodies. Clin Chim Acta 134: 327-336.

26) Snedecor GW, Cocharan WG. 1967. Statistical Methods, p 285-338. Iowa State University Press, Ames, IA.

27) Murase T, Mizuno T, Omachi T, Onizawa K, Komine Y, Kondo H, Hase T, Tokimitsu I. 2001. Dietary diacylglycerol suppresses high fat and high sucrose diet-induced body fat accumulation in C57BL/6J mice. J Lipid Res 42: 372-378.

28) Sugimoto T, Kimura T, Fukuda H, Iritani N. 2003. Comparisons in glucose and lipid metabolism in rat fed diacylglycerol oil and triacylglycerol oil. J Nutr Sci Vitaminol 49: 47-55.

29) Iritani N, Kimura T, Fukuda H, Sugimoto T. 2000. Effects of dietary fatty acid on tissue fatty acid compositions in rats. J Jpn Soc Nutr Food Sci 53: 249-257.

30) Griffin ME, Marcucci MJ, Cline GW, Bell K, Barucci N, Lee D, Goodyear LJ, Kraege EW, White MF, Shulman GI. 1999. Free fatty acid-induced insulin resistance is associated with activation of protein kinase $\mathrm{C}$ theta and alterations in the insulin signaling cascade. Diabetes $\mathbf{4 8}$ : 1270-1274. 